\title{
Suspension of anticytomegalovirus maintenance therapy following immune recovery due to highly active antiretroviral therapy
}

\author{
André L L Curi, Acácio Muralha, Lilia Muralha, Carlos Pavesio
}

\begin{abstract}
Aim-To describe the authors' experience with discontinuation of anticytomegalovirus (CMV) maintenance therapy in patients showing immune recovery following highly active antiretroviral therapy (HAART).

Methods-Retrospective analysis of the records of 41 patients who presented with CMV retinitis and whose maintenance therapy was discontinued from March 1997 to December 1999.

Results-41 patients had their anti-CMV therapy discontinued. The mean follow up after discontinuation of maintenance therapy in April 2000 was 20.4 months. At the time of discontinuation of maintenance therapy the lowest CD4+ count was 143 cells $\times 10^{6} / 1$ and only three patients had detectable HIV viral load. No reactivation or progression was seen in any of these patients after suspension of maintenance therapy.

Conclusion-The anti-CMV maintenance therapy could be discontinued safely in patients with CD4+ above 150 cells $\times 10^{6} / 1$ although close follow up remains necessary especially in patients whose CD4+ count drops below this level.

(Br f Ophthalmol 2001;85:471-473)
\end{abstract}

Department of Ophthalmology Fluminense Federal University, Niterói, Brazil

A L L Curi

A Muralha

L Muralha

Moorfields Eye Hospital, London, UK A L L Curi

C Pavesio

Correspondence to: Carlos Pavesio, Moorfields Eye Hospital, City Road, London EC1V 2PD, UK Carlos.Pavesio@

moorfields.nthames.nhs.uk

Accepted for publication 18 October 2000 of the disease depend CMV drug and routes of delivery used vary. The treatment for CMV retinitis is usually divided into two phases - induction and maintenance. Until recently discontinuation of maintenance therapy was not a possibility since the drugs are virustatic and treatment against HIV infection was unable to improve the patient immune status.

After the introduction of HAART (highly active antiretroviral therapy) some clinical features of CMV retinitis have changed due to immune recovery. ${ }^{2}$ This potent anti-HIV therapy leads to an increase in CD4+ counts and a control of HIV replication resulting in decrease of viral load. As the development of CMV retinitis is directly linked to $\mathrm{CD} 4+$ counts and host immunity, the increase in the CD4+ count itself may lead to control of the disease without specific therapy. Based on this, some authors have attempted discontinuation of maintenance anti-CMV therapy for those patients who have shown immune recovery; however, the level of recovery at which this could be safely done has not yet been clearly defined. ${ }^{3-5}$

The goal of this paper was to describe the authors' experience with the discontinuation of maintenance anti-CMV therapy and to discuss when therapy could be stopped safely.

\section{Patients and methods}

The authors reviewed the records of HIV positive patients who had CMV retinitis, and whose maintenance therapy had been discontinued, between March 1997 and December 1999. Forty one patients had their anti-CMV therapy discontinued. Patients were considered for discontinuation of maintenance anti-CMV treatment if they were on HAART and had shown an increase of their CD4+ above 100 cells $\times 10^{6} / 1$ in one single test, and had an undetectable HIV viral load, which was regarded as a good response to HAART. The duration of HAART therapy before discontinuation of anti-CMV therapy was not taken into consideration. These parameters (CD4+ counts and HIV viral load) were monitored every 3 months. All patients were examined by indirect ophthalmoscopy after pupillary dilatation every 2 weeks. The final data analysis was considered in April 2000.
Results (Table 1)

Out of 41 patients $33(80.5 \%)$ were male and eight $(19.5 \%)$ female. The mean age was 35.5 years ranging from 22 to 56 . Thirty one $(75.6 \%)$ patients had bilateral disease and 10 $(24.4 \%)$ unilateral, reaching a total of 72 affected eyes.

At the time of the diagnosis of CMV retinitis the mean CD $4+$ counts was 44.6 cells $\times 10^{6} / 1$ (range 3-102, median 42). The mean duration of CMV retinitis treatment was 20.4 months 
Table 1 Patient characteristics and treatment

\begin{tabular}{|c|c|c|c|c|c|c|c|c|c|}
\hline Patient No & Age & $\begin{array}{l}\text { CD4+ } \\
\text { count at } \\
\text { CMV DX }\end{array}$ & $\begin{array}{l}\text { Initial CMV } \\
\text { therapy }\end{array}$ & $\begin{array}{l}\text { Duration of } \\
\text { CMV } \\
\text { therapy } \\
\text { (months) }\end{array}$ & $\begin{array}{l}\text { CD4+ count } \\
\text { when } C M V \\
\text { therapy } \\
\text { stopped }\end{array}$ & $\begin{array}{l}\text { HIV viral } \\
\text { load when } \\
\text { CMV } \\
\text { therapy } \\
\text { stopped }\end{array}$ & $\begin{array}{l}\text { Follow up } \\
\text { since CMV } \\
\text { therapy } \\
\text { stopped } \\
\text { (months) }\end{array}$ & $\begin{array}{l}\text { Duration of } \\
\text { HAART } \\
\text { before CMV } \\
\text { therapy }\end{array}$ & $\begin{array}{l}\text { CD4+ count } \\
\text { at last visit }\end{array}$ \\
\hline 1 & 35 & 27 & IV GCV & 36 & 326 & UND & 24 & 23 & 675 \\
\hline 2 & 41 & 65 & IV GCV & 8 & 235 & UND & 30 & 7 & 483 \\
\hline 3 & 43 & 12 & IV GCV & 32 & 212 & UND & 33 & 15 & 296 \\
\hline 4 & 28 & 11 & IV GCV & 17 & 262 & UND & 22 & 18 & 821 \\
\hline 5 & 39 & 25 & IV GCV & 36 & 318 & UND & 22 & 21 & 798 \\
\hline 6 & 27 & 3 & IV GCV & 39 & 449 & UND & 24 & 20 & 806 \\
\hline 7 & 56 & 62 & IV GCV & 29 & 274 & UND & 27 & 22 & 383 \\
\hline 8 & 38 & 31 & IV GCV & 16 & 306 & UND & 29 & 16 & 402 \\
\hline 9 & 33 & 7 & IV GCV & 41 & 295 & UND & 18 & 31 & 493 \\
\hline 10 & 34 & 43 & IV GCV & 30 & 273 & UND & 27 & 22 & 286 \\
\hline 11 & 34 & 46 & IV GCV & 30 & 273 & UND & 27 & 21 & 461 \\
\hline 12 & 47 & 54 & IV GCV & 19 & 238 & UND & 26 & 19 & 819 \\
\hline 13 & 45 & 102 & IV GCV & 7 & 296 & UND & 21 & 6 & 360 \\
\hline 14 & 37 & 76 & IV GCV & 8 & 231 & UND & 31 & 7 & 292 \\
\hline 15 & 37 & 12 & IV GCV & 31 & 274 & UND & 20 & 29 & 323 \\
\hline 16 & 37 & 95 & IV GCV & 8 & 297 & UND & 31 & 7 & 450 \\
\hline 17 & 41 & 6 & IV GCV & 24 & 216 & UND & 22 & 22 & 427 \\
\hline 18 & 39 & 18 & IV GCV & 25 & 287 & UND & 23 & 25 & 545 \\
\hline 19 & 36 & 6 & IV GCV & 23 & 347 & UND & 30 & 19 & 738 \\
\hline 20 & 29 & 86 & IV GCV & 11 & 295 & UND & 19 & 15 & 463 \\
\hline 21 & 28 & 96 & IV GCV & 17 & 286 & UND & 19 & 21 & 374 \\
\hline 22 & 34 & 35 & IV GCV & 13 & 219 & UND & 21 & 5 & 296 \\
\hline 23 & 29 & 25 & IV GCV & 18 & 379 & UND & 21 & 11 & 542 \\
\hline 24 & 30 & 55 & IV GCV & 7 & 275 & UND & 21 & 8 & 293 \\
\hline 25 & 22 & $\mathrm{n} / \mathrm{a}$ & IV GCV & 38 & 304 & 230 & 14 & 13 & 581 \\
\hline 26 & 38 & 27 & IV GCV & 41 & 489 & 321 & 14 & 28 & 872 \\
\hline 27 & 37 & 8 & IV GCV & 21 & 184 & UND & 37 & 7 & 422 \\
\hline 28 & 39 & 26 & IV GCV & 43 & 176 & UND & 24 & 20 & 506 \\
\hline 29 & 27 & 87 & IV GCV & 16 & 163 & UND & 21 & 17 & 285 \\
\hline 30 & 31 & 36 & IV GCV & 22 & 169 & UND & 22 & 13 & 618 \\
\hline 31 & 36 & 32 & IV GCV & 15 & 158 & UND & 18 & 6 & 373 \\
\hline 32 & 34 & 45 & IV GCV & 11 & 156 & UND & 21 & 8 & 747 \\
\hline 33 & 31 & 27 & IV GCV & 9 & 149 & UND & 18 & 7 & 216 \\
\hline 34 & 39 & 62 & IV GCV & 25 & 152 & UND & 17 & 11 & 181 \\
\hline 35 & 41 & 74 & IV GCV & 9 & 185 & UND & 5 & 9 & 335 \\
\hline 36 & 33 & 46 & IV GCV & 11 & 171 & UND & 7 & 10 & 562 \\
\hline 37 & 38 & 65 & IV GCV & 9 & 146 & UND & 6 & 9 & 268 \\
\hline 38 & 35 & 73 & IV GCV & 10 & 162 & UND & 6 & 10 & 194 \\
\hline 39 & 32 & 41 & IV GCV & 10 & 181 & UND & 7 & 9 & 308 \\
\hline 40 & 37 & 71 & IV GCV & 9 & 168 & UND & 7 & 13 & 452 \\
\hline 41 & 28 & 67 & IV GCV & 13 & 143 & UND & 6 & 8 & 312 \\
\hline Mean & 35.5 & 44.6 & & 20.4 & 246.8 & 275.5 & 20.4 & 14.8 & 464.8 \\
\hline Maximun & 56 & 102 & & 43 & 489 & 321 & 37 & 31 & 872 \\
\hline Minimun & 22 & 3 & & 7 & 143 & 230 & 5 & 5 & 181 \\
\hline Median & 36 & 42 & & 17 & 238 & 275.5 & 21 & 13 & 427 \\
\hline
\end{tabular}

$\mathrm{CMV}=$ cytomegalovirus retinitis; IV GCV $=$ intravenous ganciclovir; HAART $=$ highly active antiretroviral therapy; UND = undetectable.

(range 7-23, median 17). All patients were initially treated with intravenous ganciclovir. Two $(4.8 \%)$ patients had an intraocular sustained release device of ganciclovir (Vitraset, Chiron Vision) implanted. After 6 months one (2.4\%) of these patients was put back on intravenous ganciclovir and the other was not put on any other form of anti-CMV treatment. Five $(12.2 \%)$ patients presented with one episode of reactivation of the retinitis during maintenance treatment and were treated with intravenous ganciclovir at induction levels. After good response to HAART therapy the patients had their anti-CMV maintenance therapy discontinued. The mean CD4+ count at this time was 246.8 cells $\times 10^{6} / 1$ (range $143-489$, median 238 ) and only two $(4.8 \%)$ patients showed detectable HIV viral load. The mean duration of HAART was 14.8 months (range 5-31, median 13). The mean duration of follow up after discontinuation of therapy and April 2000 was 20.4 months (range 5-37, median 21). Eleven $(26.8 \%)$ patients had been followed for more 24 months, 23 (56.1\%) between 12 and 24 months, and seven (17.1\%) for less than 12 months. Eight patients (19.5\%), 13 eyes, with inactive retinitis developed cystoid macular oedema (CMO) secondary to immune recovery. All patients who presented with CMO initially presented with peripheral CMV retinitis. One patient $(2.4 \%)$ presented with unilateral optic disc neovascularisation. The mean CD4+ count at last assessment was 464.8 cells $\times 10^{6} / 1$ (range 181-872, median 427). No reactivation or progression of the retinitis was seen in any of these patients after discontinuation of the maintenance therapy.

\section{Discussion}

Since the advent of HAART many authors have shown that anti-CMV maintenance therapy could be discontinued following immune recovery. ${ }^{3-5}$ CD $4+$ counts, HIV viral load, and CMV viraemia are the factors that have been most frequently used to monitor immune recovery. ${ }^{6}$ In our retrospective study of 41 patients who had their anti-CMV therapy discontinued following good response to HAART, all patients had CD4+ counts above 100 cells $\times 10^{6} / 1$ and only two patients had detectable HIV viral load at the time therapy was stopped. Even though an undetectable 
HIV viral load had been established as a minimal requirement for discontinuation of antiCMV therapy, these two patients requested interruption of their treatment following CD4+ increase.

The level of recovery (CD4, HIV viral load) at which anti-CMV therapy can be safely discontinued is still debatable. Authors have considered CD4+ counts above 100 cells $\times 10^{6} / 1$ as safe for stopping anti-CMV therapy. ${ }^{3}$ Macdonald et al considered CD4+ counts above 50 cells $\times 10^{6} / 1$ for 3 months to discontinued anti-CMV therapy, although in their series only two presented with CD4+ counts below 100 cells $\times 10^{6} / 1{ }^{7}$ This result does not support a recommendation for discontinuation of therapy below 100 cells $\times 10^{6} / 1$. Even though there are a few cases in which CMV retinitis relapsed in spite of a higher CD4+ count, this factor remains as the single most important to be considered when deciding to discontinue maintenance therapy. ${ }^{8}$ The proliferation of specific clones of anti-CMV $\mathrm{T}$ lymphocytes may be important in the control of the retinal infection, and this has been demonstrated by a study which showed that the presence of active end organ disease had a strong correlation with loss of CMV specific lymphocyte response. ${ }^{9}$ The same authors state that this specific immune recovery was stimulated by HAART. ${ }^{9}$ Unfortunately this kind of test is not practical in the clinical setting, and our data, and those of others, do not support its regular use. However, it may become useful in situations where discontinuation of anti-CMV therapy is to be attempted in someone with a CD4+ count lower than 150 cells $\times 10^{6} / 1$.

Song et al demonstrated that a decrease of CD4+ cells below 50 cells $\times 10^{6} / 1$ following HAART failure increased the risk of CMV retinitis reactivation, and that the increase in the HIV viral load was not predictive of reactivation. This value of 50 cells $\times 10^{6} / 1$ has been shown to be important both for the development and the reactivation of CMV retinitis. They also stated that even though the maintenance therapy can be discontinued there is no guarantee that CMV retinitis will not relapse and that these patients should be followed closely, especially those showing failure with HAART. ${ }^{10}$ In our study, none of the patients showed reactivation of $\mathrm{CMV}$ retinitis after a mean follow up of 20.4 months, with over $50 \%$ of them having been followed for over 1 year, including those patients who had detectable HIV viral load. None of our patients presented with CD4+ counts at the last assessment below the level at which they had their anti-CMV therapy stopped.

The mean CD4+ count at the time of diagnosis of CMV retinitis, and the duration of CMV retinitis did not seem to influence recovery and do not represent risk factors for reactivation of CMV retinitis following HAART. History of previous relapses during maintenance therapy, requiring re-induction therapy, also did not seem to represent a risk factor for poor response.
Mitchell et al demonstrated that patients responsive to HAART within 3 months and previous CMV retinitis did not show reactivation of the disease. ${ }^{11}$ All patients in our study had been on HAART for at least 5 months when anti-CMV therapy was discontinued, even though the duration of HAART was not considered as a criterion for discontinuation of therapy.

Whitcup et al in a prospective study found that patients with CD4+ counts above 150 cells $\times 10^{6} / 1$ could have their anti-CMV maintenance therapy discontinued safely. ${ }^{12}$ In our study, even though the criterion for discontinuation had been established at 100 cells $\times 10^{6} / 1$ only three patients had a value lower than 150 cells $\times 10^{6} / 1$. These data only allow us to conclude that levels above 150 cells $\times 10^{6} / 1$ are safe. Only a much larger number of individuals with lower counts will allow us to make a different recommendation. Another important aspect to be considered is related to the fact that this decision about CD4 count level was made around 3 years ago, at a time when nearly no data were available on this subject. The level of 100 cells $\times 10^{6} / 1$ was considered to be a reasonable level at that time, and until now there are no convincing data that lower levels are safe. Close follow up of these patients remains necessary, especially when CD4+ count drops below this established level.

1 Kupperman BD, Petty JG, Richman DD, et al. Correlation between CD4+ counts and prevalence of cytomegalovirus retinitis and human immunodeficiency virus-related noninfectious retinal vasculopathy in patients with acquired immunodeficiency syndrome. Am $\mathcal{f}$ Ophthalmol 1993;115:527-82.

2 Karavellas MP, Lowder CY, MacDonald C, et al. Immune recovery vitreitis associated with inactive cytomegalovirus retinitis-a new syndrome. Arch Ophthalmol 1998;116: 169-75.

3 Vabrec TR, Baldassano VF, Whitcup SM. Discontinuation of maintenance therapy in patients with quiescent cytomegalovirus and elevated CD4+ counts. Ophthalmology 1998; 105:1259-64

4 Tural C, Romeo J, Sirera G, et al. Long-lasting remission of cytomegalovirus retinitis without maintenance therapy in human immunodeficiency virus-infected patients. F Infect Dis 1998;177:1080-3.

5 MacDonald JC, Torriani FJ, Morse LS, et al. Lack of reactivation of cytomegalovirus (CMV) retinitis after stopping CMV maintenance therapy in AIDS patients with sustained elevation in CD4 T cells in response to highly active antiretroviral therapy. F Infect Dis 1998;177:1182-7.

6 Postelmans L, Gerard M, Sommerreijns B, et al. Discontinuation of maintenance therapy for CMV retinitis in AIDS patients on highly active antiretroviral therapy. Ocul Immupatients on highly active antiretrc
nol Inflamm 1999;7:199-203.

7 Macdonald JC, Karavellas M, Torriani FJ, et al. Highly active antiretroviral therapy-related immune recovery in AIDS patients with cytomegalovirus retinitis. Ophthalmology 2000;107:877-80.

8 Petit N, Zandotti C, Riss JM, et al. Relapse of CMV retinitis in an AIDS patient with high CD4 counts. F Antimicrob Chemother 1998;41:666-7.

9 Komanduri KV, Viswanathan MN, Weider ED, et al. Restoration of cytomegalovirus-specific CD4 T-lymphocyte responses after ganciclovir and highly active antiretroviral responses after ganciclovir and highly active antiretroviral 56.

10 Song M, Karavellas MP, MacDonald JC, et al. Characterization of reactivation of cytomegalovirus retinitis in patients healed after treatment with highly active antiretroviral therapy. Retina 2000;20:151-5.

11 Mitchell SM, Membrey WL, Youle MS, et al. Cytomegalovirus retinitis after the initiation of highly active antiretroviral therapy: a 2 year prospective study. $B r$ F Ophthalmol 1999; 83:652-5.

12 Whitcup SM, Fortin E, Lindblad AS, et al. Discontinuation of anticytomegalovirus therapy in patients with HIV infection and cytomegalovirus retinitis. $\mathscr{F A M A}$ 1999;282:16337 . 